\title{
Assessment of Single and Precise Point Positioning Over Long Observational Periods
}

\author{
Mohamed El-Tokhey \\ Public Works Department \\ Faculty of Engineering, Ain Shams University \\ Cairo, Egypt
}

\author{
Ahmed Ragheb \\ Public Works Department \\ Faculty of Engineering, Ain Shams University \\ Cairo, Egypt
}

\author{
Tarek Hassan \\ Public Works Department \\ Faculty of Engineering, Ain Shams University \\ Cairo, Egypt
}

\begin{abstract}
In this work, the accuracy of using Single Point Positioning (SPP) and Precise Point Positioning (PPP) techniques is assessed in case of using long observational periods. Positioning using Differential Global Navigation Satellite System (DGNSS) technique is adopted to achieve reliable accurate results to be used as a reference in the evaluation process for both SPP and PPP positioning techniques. A number of neighboring International GNSS Service (IGS) stations were participated in this study for the differential positioning. GNSS data over one month for a continuous operating station at Faculty of Engineering, Ain Shams University were collected and processed on a daily basis in the SPP and PPP processing modes. In addition, DGNSS processing sessions using the IGS stations were carried out for each day of the month. The positional differences for both SPP and PPP solutions with respect to the DGNSS solutions were computed. The results showed that the SPP solutions had positional differences with mean value $23.4 \mathrm{~cm}$, while the PPP solutions had positional differences with mean value $12.7 \mathrm{~cm}$. In addition, by considering a unique monthly solution for each technique, the positional difference reaches to $15 \mathrm{~cm}$ in case of the SPP solution and $12.5 \mathrm{~cm}$ in case of the PPP solution. Thus, applications that do not require immediate positioning, such as wildlife management and insect infestation, can benefit from these results with low-cost hardware components. In addition, monitoring significant tectonic motions caused by earthquakes is another application in this context.
\end{abstract}

Keywords-DGNSS, IGS, PPP, SPP.

\section{INTRODUCTION}

In recent years, there has been continuous interest in achieving high positional accuracy using a single GNSS receiver (standalone receiver). The need to lower the costs of differential (relative) positioning using multiple receivers in addition to saving time and effort while occupying multiple stations have always pushed for accelerating steps to achieve prompt higher positional accuracy using single receiver.

GNSS has shown the capacity to deliver much improved positioning services and accuracy due to the modernization of the satellite system, significantly upgraded error estimation models, much increased mobility for the end-user receivers, and more reliable and rapid integer ambiguity resolution approaches [1].

The coordinates of a single point are determined by point positioning when using a single receiver while measuring pseudoranges to (normally four or more) satellites. Instead of "point positioning", the term "Single Point Positioning" or "SPP" is used [2]. Various relevant references always emphasize that SPP is suitable for navigation and not for surveying works as the positioning accuracy degrades to few meters due to different biases caused by the ionosphere and troposphere signal propagation media, satellite clock, orbital data and other evolving errors [2]. This study discusses how far the SPP solution accuracy can reach by using long observational periods of GNSS data.

Also, this study discusses the positioning accuracy of another breakthrough in the GNSS field which is the precise point positioning technique (PPP). IGS has ensured open access and high-quality GNSS data products since 1994. These products enable access to the definitive global reference frame for different scientific and commercial applications. IGS products include different information such as GNSS satellite ephemerides and satellite clock information, which can be used to provide orbit/clock corrections for the PPP solutions.

A number of software packages can be used to process the GNSS data in both SPP and PPP processing modes. The used software in this study is RTKLIB version 2.4.2 which is an open source program package for standard and precise positioning with GNSS. RTKLIB employs an iterated weighted Least Square Estimation (LSE) for the SPP mode, while it uses Extended Kalman Filter (EKF) estimation process for the PPP mode [3].

The assessment strategy for both SPP and PPP techniques relies on the existence of a continuous operating station at Faculty of Engineering, Ain Shams University to collect GNSS data over long period (one month in this study). DGNSS solutions for the collected data are obtained, by involving six neighboring IGS stations in the processing sessions, to be used as a reference in the evaluation process for the quality and applicable usability of both SPP and PPP positioning techniques.

\section{COLLECTED DATA}

The GNSS data used in the different processing stages in this study were acquired from the continuous operating station at Faculty of Engineering, Ain Shams University with a Trimble NetR9 GNSS reference receiver which offers 440 
channels for GNSS multiconstellation tracking performance and supports a wide range of satellite signals. Currently, the NetR9 platform is capable of tracking signals from GPS, GLONASS, Galileo, Beidou, and QZSS constellations [4]. GNSS data from these constellations will be used in this study. The continuous operating station at Faculty of Engineering, Ain Shams University was given the name "SHMS". More details about the establishment and operation of this station can be found in [5].

Receiver INdependent EXchange (RINEX) data files for the observations of SHMS station in June, 2017 were acquired in the form of 30 one-day RINEX data files with one second sampling rate; one file for each day of the month. Also, the IGS final orbits files were acquired from the Crustal Dynamics Data Information System (CDDIS) data center which is one of the IGS data centers that can be used to download the different IGS products and the RINEX data files for all IGS stations.

For the SPP and PPP processing modes, the acquired RINEX data files for SHMS station and the files of the IGS final orbits (for PPP) are sufficient to proceed on the processing stage. However, the DGNSS processing mode is not that simple and other data are needed. Basically, it is essential to obtain the RINEX data files for a number of available neighboring IGS stations in the form of 30 one-day RINEX files; one for each day of month June, 2017. The chosen IGS stations to be involved in this study are listed in Table I, while Figure 1 shows the location of the used IGS stations, in addition to SHMS station.

TABLE I. CHOSEN IGS STATIONS INVOLVED IN THE IGS DGNSS TECHNIQUE

\begin{tabular}{|c|c|}
\hline Site & ID \\
\hline NICOSIA-ATHALASSA & NICO \\
\hline Noto & NOTl \\
\hline Ohrid & ORID \\
\hline Haifa & BSHM \\
\hline Mitzpe Ramon & RAMO \\
\hline Metzoki Dragot & DRAG \\
\hline
\end{tabular}

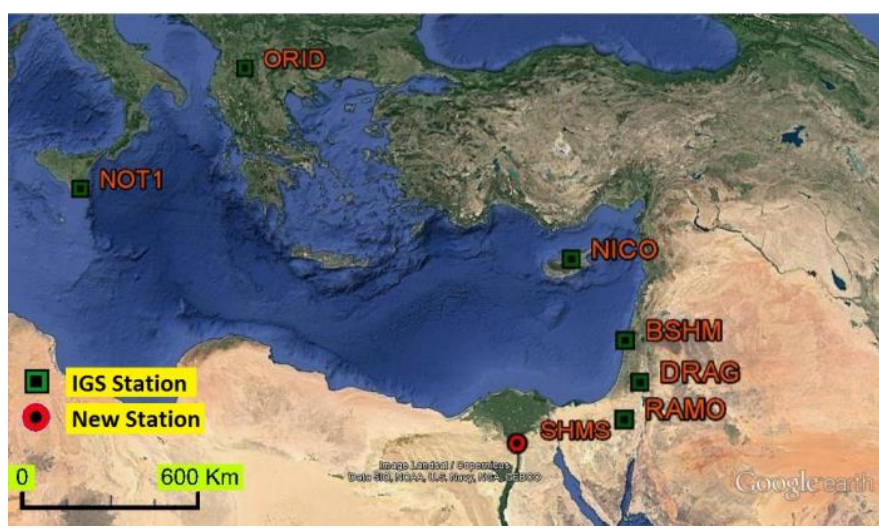

Fig. 1. Involved IGS stations along with SHMS station

In addition, and to relate all processing and analysis stages to a specific reference system, International Terrestrial Reference Frame 2008 (ITRF2008) is adopted in this study. Position coordinates for the chosen IGS stations were obtained from the ITRF website [6] to be used in the DGNSS processing mode as constraints. ITRF2008 coordinates for all chosen stations were obtained for the 30 days of the month (at epochs 1/6/2017, 2/6/2017, 3/6/2017, .........., 30/6/2017).

It should be noted that the World Geodetic System 1984 (WGS84) - G1762 reference frame compared to ITRF2008 shows Root Mean Square (RMS) difference of one centimeter overall [7]. Comparisons between the National GeospatialIntelligence Agency (NGA) GPS precise ephemerides, referenced to WGS84 (G1762), and the IGS GPS precise ephemerides, referenced to ITRF2008, validate that the two reference systems are consistent. This indicates that these two reference frames are essentially identical with differences being statistically insignificant for most applications [7]. This note is necessary to avoid any confusion caused by referencing the SPP and PPP solutions to the WGS84 reference system while referencing the DGNSS solutions to the International Terrestrial Reference System (ITRS).

\section{DATA PROCESSING}

As discussed earlier, the collected data were processed in three modes: DGNSS, SPP and PPP.

DGNSS processing mode was performed once for each day of the month and for this processing mode, Trimble Business Center (TBC) software was used. The input data for each processing session (each day) are the RINEX files for SHMS station and the used IGS stations at this day in addition to the corresponding ITRF2008 coordinates of each IGS station to be used as constraints in the adjustment solution.

The GNSS observables collected at reference stations for the post-processing positioning are likely to be provided by a public data service on a routine basis with a large sampling interval of 30 seconds. This low-rate data might lead to nonmatching observations with another high-rate data, e.g., sampling interval of one second or five seconds [8]. In this study, the RINEX data files acquired from SHMS station are of one-second sampling interval, while the RINEX data files acquired from the used IGS stations have a sampling interval of 30 seconds. To achieve the highest possible accuracy for using one-second sampling interval in the differential solutions, GNSS observables are required to have the same sampling interval for the two baseline stations. Consequently, the DGNSS solutions in this study will adopt a 30-second sampling interval in the processing stage. In addition, it should be noted that there are a number of implemented algorithms and techniques for pseudorange and carrier phase reference station data interpolation at a high level of accuracy to overcome the sampling interval synchronization problem. In [8] and [9], detailed discussions concerning this issue are presented.

Finally, the DGNSS processing sessions were performed for each day keeping in mind that at least, four IGS stations participated in each session. The absence of one or two stations at any session is caused by the unavailability of some IGS stations RINEX data files at this day. The GNSS final orbits files were used in the processing while the most desirable mask angle of 15 degrees was guaranteed [10]. Table II shows statistics of standard deviations of the resulted coordinates in the X-direction $\left(\sigma_{\mathrm{x}}\right)$, in the $\mathrm{Y}$-direction $\left(\sigma_{\mathrm{y}}\right)$ and in the Zdirection $\left(\sigma_{\mathrm{z}}\right)$ over the month for DGNSS solutions. 
TABLE II. STATISTICS OF STANDARD DEVIATIONS OF THE RESULTED COORDINATES OVER THE MONTH FOR DGNSS

\begin{tabular}{|c|c|c|c|}
\hline \multicolumn{4}{|c}{ SOLUTIONS } \\
\hline Value & $\sigma_{\mathrm{x}}(\mathrm{m})$ & $\sigma_{\mathrm{y}}(\mathrm{m})$ & $\sigma_{\mathrm{z}}(\mathrm{m})$ \\
\hline Minimum & 0.016 & 0.011 & 0.012 \\
\hline Maximum & 0.047 & 0.026 & 0.036 \\
\hline Mean & 0.029 & 0.017 & 0.022 \\
\hline
\end{tabular}

RTKLIB software was used to process the data in both SPP and PPP modes. SPP processing is performed once for each day of the month using the acquired RINEX data for SHMS station. The broadcast ephemeris is the adopted satellite ephemeris in this mode, Ionospheric Free Linear Combination (Iono-Free LC) is used as an ionosphere correction, Estimated Zenith Total Delay (Estimated ZTD) is used as a troposphere correction which was recommended by [11], while the used mask angle is 15 degrees. Table III shows statistics of $\sigma_{x}, \sigma_{y}$ and $\sigma_{z}$ of the resulted coordinates over the month.

TABLE III. STATISTICS OF STANDARD DEVIATIONS OF THE RESULTED COORDINATES OVER THE MONTH FOR SPP

\begin{tabular}{|c|c|c|c|}
\hline \multicolumn{4}{|c}{ SOLUTIONS } \\
\hline Value & $\sigma_{\mathrm{x}}(\mathrm{m})$ & $\sigma_{\mathrm{y}}(\mathrm{m})$ & $\sigma_{\mathrm{z}}(\mathrm{m})$ \\
\hline Minimum & 0.007 & 0.005 & 0.004 \\
\hline Maximum & 0.008 & 0.006 & 0.006 \\
\hline Mean & 0.009 & 0.005 & 0.005 \\
\hline
\end{tabular}

PPP processing mode is also performed once for each day of the month using the acquired RINEX data for SHMS station. Unlike the SPP processing mode, the files of the IGS final orbits (precise ephemeris files) are used in the PPP processing mode while using the same processing parameters regarding ionosphere correction, troposphere correction and mask angle. Table IV shows statistics of $\sigma_{\mathrm{x}}, \sigma_{\mathrm{y}}$ and $\sigma_{\mathrm{z}}$ of the resulted coordinates over the month.

TABLE IV. STATISTICS OF STANDARD DEVIATIONS OF THE RESULTED COORDINATES OVER THE MONTH FOR PPP

\begin{tabular}{|c|c|c|c|}
\hline \multicolumn{4}{|c}{ SOLUTIONS } \\
\hline Value & $\sigma_{\mathrm{x}}(\mathrm{m})$ & $\sigma_{\mathrm{y}}(\mathrm{m})$ & $\sigma_{\mathrm{z}}(\mathrm{m})$ \\
\hline Minimum & 0.004 & 0.003 & 0.002 \\
\hline Maximum & 0.004 & 0.003 & 0.003 \\
\hline Mean & 0.004 & 0.003 & 0.002 \\
\hline
\end{tabular}

Figures 2, 3, and 4 show the resulted coordinate variations over the month for the $\mathrm{X}, \mathrm{Y}$, and $\mathrm{Z}$ coordinates, respectively, in case of using the DGNSS, SPP and PPP positioning techniques. For publication purposes, certain number was subtracted from all $\mathrm{X}$ coordinates in Figure 2 and the same procedure was done for $\mathrm{Y}$ and $\mathrm{Z}$ coordinates in Figures 3 and 4, respectively.

It is clear from Figures 2, 3 and 4 that DGNSS solutions are the most stable solutions and this result was expected. This stability in addition to the reliability of DGNSS solutions are the reasons behind choosing these solutions as reference in the assessment process for both SPP and PPP solutions. In addition, the figures show that PPP soultions are much more stable than SPP solutions and the fluctuation in SPP solutions from one day to another is clear.
It is well known that the accuracy of SPP and PPP solutions degrades with shorter observation periods. For completeness here, three additional processing sessions were performed to give a quick indication to the accuracy of SPP and PPP solutions in case of using a short observation period (4-hour observation period). A sample of 4-hour observation period, from 1 June 2017, was processed in the DGNSS, SPP and PPP modes to check the differences resulted between both SPP and PPP solutions and the DGNSS solution. The same processing parameters, used earlier to process the 24-hour observation periods in the different modes, were used here to process the 4hour observation period.

Table $\mathrm{V}$ shows $\sigma_{\mathrm{x}}, \sigma_{\mathrm{y}}$ and $\sigma_{\mathrm{z}}$ of the resulted coordinates using 4-hour observation period.

TABLE V. STANDARD DEVIATIONS OF THE RESULTED COORDINATES USING 4-HOUR OBSERVATION PERIOD

\begin{tabular}{|c|c|c|c|}
\hline Mode & $\sigma_{\mathrm{x}}(\mathrm{m})$ & $\sigma_{\mathrm{y}}(\mathrm{m})$ & $\sigma_{\mathrm{z}}(\mathrm{m})$ \\
\hline DGNSS & 0.046 & 0.028 & 0.036 \\
\hline SPP & 0.012 & 0.009 & 0.008 \\
\hline PPP & 0.010 & 0.006 & 0.006 \\
\hline
\end{tabular}

\section{DATA ANALYSIS AND RESULTS}

At this stage, the DGNSS solutions are considered as the reference in the evaluation process of the quality and accuracy of the SPP and PPP solutions. Based on this consideration, the daily coordinate differences between the SPP and the DGNSS solutions as well as the daily coordinate differences between the PPP and the DGNSS solutions were computed using the following equations:

$$
\begin{gathered}
\Delta X=X-X_{D G N S S} \\
\Delta Y=Y-Y_{D G N S S} \\
\Delta Z=Z-Z_{D G N S S} \\
\Delta P=\sqrt{\Delta X^{2}+\Delta Y^{2}+\Delta Z^{2}}
\end{gathered}
$$

where

$\Delta X, \Delta Y$ and $\Delta Z$ are the coordinate differences in the $X, Y$ and $Z$ directions, respectively.

$X, Y$ and $Z$ are the resulted SPP or PPP coordinates.

$X_{D G N S S}, Y_{D G N S S}$ and $Z_{D G N S S}$ are the resulted DGNSS coordinates.

$\Delta P$ is the positional difference between DGNSS solution and SPP solution or PPP solution.

For the resulted coordinates using 4-hour observation period, the differences between both SPP and PPP solutions and the DGNSS solution are listed in Table VI.

TABLE VI. COORDINATE DIFFERENCES BETWEEN THE SPP AND PPP SOLUTIONS AND THE DGNSS SOLUTION

\begin{tabular}{|c|c|c|c|c|}
\hline Modes & $\Delta X(\mathrm{~m})$ & $\Delta Y(\mathrm{~m})$ & $\Delta Z(\mathrm{~m})$ & $\Delta P(\mathrm{~m})$ \\
\hline SPP-DGNSS & 0.629 & 0.278 & 0.513 & 0.858 \\
\hline PPP-DGNSS & 0.155 & -0.172 & 0.050 & 0.237 \\
\hline
\end{tabular}

Table VI emphasized large positional differences that resulted from using only 4-hour observation period. On the 
other hand, Table VII shows the resulting coordinate differences between PPP and DGNSS solutions, while Table VIII shows the resulting coordinate differences between SPP and DGNSS solutions using 24-hour observation period. In addition, these differences are plotted together in Figure 5.

TABLE VII. RESULTING COORDINATE DIFFERENCES BETWEEN PPP AND DGNSS SOLUTIONS

\begin{tabular}{|c|c|c|c|c|}
\hline Day & $\Delta X_{P-D}(\mathrm{~m})$ & $\Delta Y_{P-D}(\mathrm{~m})$ & $\Delta Z_{P-D}(\mathrm{~m})$ & $\Delta P_{P-D}(\mathrm{~m})$ \\
\hline 1 & 0.113 & -0.001 & 0.021 & 0.115 \\
\hline 2 & 0.136 & 0.014 & 0.029 & 0.140 \\
\hline 3 & 0.135 & 0.014 & 0.036 & 0.140 \\
\hline 4 & 0.140 & 0.021 & 0.035 & 0.145 \\
\hline 5 & 0.149 & 0.028 & 0.041 & 0.157 \\
\hline 6 & 0.122 & 0.005 & 0.022 & 0.124 \\
\hline 7 & 0.112 & 0.005 & 0.025 & 0.115 \\
\hline 8 & 0.105 & 0.002 & 0.025 & 0.108 \\
\hline 9 & 0.112 & 0.002 & 0.030 & 0.116 \\
\hline 10 & 0.076 & -0.001 & 0.014 & 0.077 \\
\hline 11 & 0.099 & -0.025 & 0.012 & 0.103 \\
\hline 12 & 0.107 & 0.016 & 0.032 & 0.113 \\
\hline 13 & 0.096 & -0.005 & 0.022 & 0.099 \\
\hline 14 & 0.116 & -0.033 & 0.015 & 0.121 \\
\hline 15 & 0.174 & 0.029 & 0.063 & 0.187 \\
\hline 16 & 0.164 & 0.022 & 0.054 & 0.174 \\
\hline 17 & 0.139 & 0.003 & 0.028 & 0.142 \\
\hline 18 & 0.141 & 0.008 & 0.035 & 0.145 \\
\hline 19 & 0.153 & 0.015 & 0.041 & 0.159 \\
\hline 20 & 0.142 & 0.030 & 0.033 & 0.149 \\
\hline 21 & 0.107 & 0.022 & 0.022 & 0.111 \\
\hline 22 & 0.122 & 0.029 & 0.031 & 0.129 \\
\hline 23 & 0.117 & 0.031 & 0.030 & 0.125 \\
\hline 24 & 0.109 & -0.012 & 0.023 & 0.112 \\
\hline 25 & 0.101 & 0.009 & 0.024 & 0.104 \\
\hline 26 & 0.105 & -0.019 & 0.030 & 0.111 \\
\hline 27 & 0.112 & -0.008 & 0.029 & 0.116 \\
\hline 28 & 0.116 & -0.002 & 0.028 & 0.119 \\
\hline 29 & 0.125 & 0.004 & 0.022 & 0.127 \\
\hline 30 & 0.129 & 0.001 & 0.023 & 0.131 \\
\hline
\end{tabular}

TABLE VIII. RESULTING COORDINATE DIFFERENCES BETWEEN SPP AND DGNSS SOLUTIONS

\begin{tabular}{|c|c|c|c|c|}
\hline Day & $\Delta X_{S-D}(\mathrm{~m})$ & $\Delta Y_{S-D}(\mathrm{~m})$ & $\Delta Z_{S-D}(\mathrm{~m})$ & $\Delta P_{S-D}(\mathrm{~m})$ \\
\hline 1 & 0.023 & -0.140 & -0.200 & 0.245 \\
\hline 2 & -0.119 & -0.169 & -0.107 & 0.233 \\
\hline 3 & -0.136 & -0.090 & -0.088 & 0.186 \\
\hline 4 & 0.102 & -0.161 & -0.019 & 0.191 \\
\hline 5 & -0.067 & -0.229 & -0.120 & 0.267 \\
\hline 6 & 0.182 & -0.127 & -0.065 & 0.231 \\
\hline 7 & -0.118 & -0.276 & -0.180 & 0.350 \\
\hline 8 & -0.121 & -0.220 & -0.160 & 0.297 \\
\hline 9 & 0.292 & -0.049 & 0.058 & 0.302 \\
\hline 10 & 0.086 & -0.238 & -0.151 & 0.295 \\
\hline 11 & -0.145 & -0.181 & -0.144 & 0.273 \\
\hline 12 & 0.112 & -0.015 & -0.208 & 0.237 \\
\hline 13 & 0.241 & 0.019 & -0.020 & 0.243 \\
\hline 14 & -0.026 & -0.234 & -0.199 & 0.308 \\
\hline 15 & 0.253 & 0.029 & 0.035 & 0.257 \\
\hline 16 & 0.306 & -0.129 & -0.062 & 0.338 \\
\hline 17 & -0.044 & -0.164 & -0.040 & 0.174 \\
\hline 18 & -0.021 & -0.120 & -0.120 & 0.171 \\
\hline 19 & 0.153 & 0.084 & 0.032 & 0.177 \\
\hline 20 & 0.223 & 0.045 & 0.050 & 0.233 \\
\hline 21 & 0.112 & -0.153 & -0.061 & 0.199 \\
\hline 22 & 0.000 & -0.023 & -0.089 & 0.092 \\
\hline 23 & 0.136 & 0.014 & -0.011 & 0.137 \\
\hline 24 & 0.122 & -0.141 & -0.112 & 0.218 \\
\hline 25 & -0.040 & -0.038 & -0.108 & 0.122 \\
\hline 26 & -0.209 & -0.328 & -0.291 & 0.485 \\
\hline 27 & 0.111 & -0.127 & 0.098 & 0.195 \\
\hline 28 & -0.039 & -0.110 & -0.166 & 0.203 \\
\hline 29 & 0.141 & -0.064 & -0.038 & 0.160 \\
\hline 30 & 0.189 & -0.063 & 0.038 & 0.203 \\
\hline
\end{tabular}

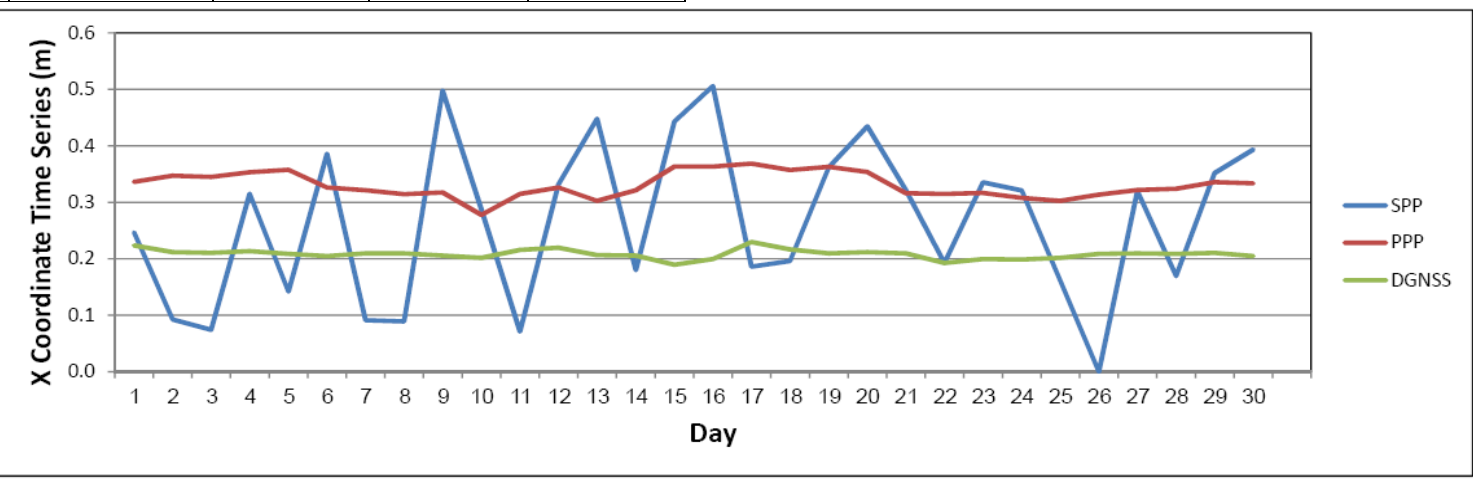

Fig. 2. X coordinate time series over the month in case of the SPP, PPP and DGNSS solutions

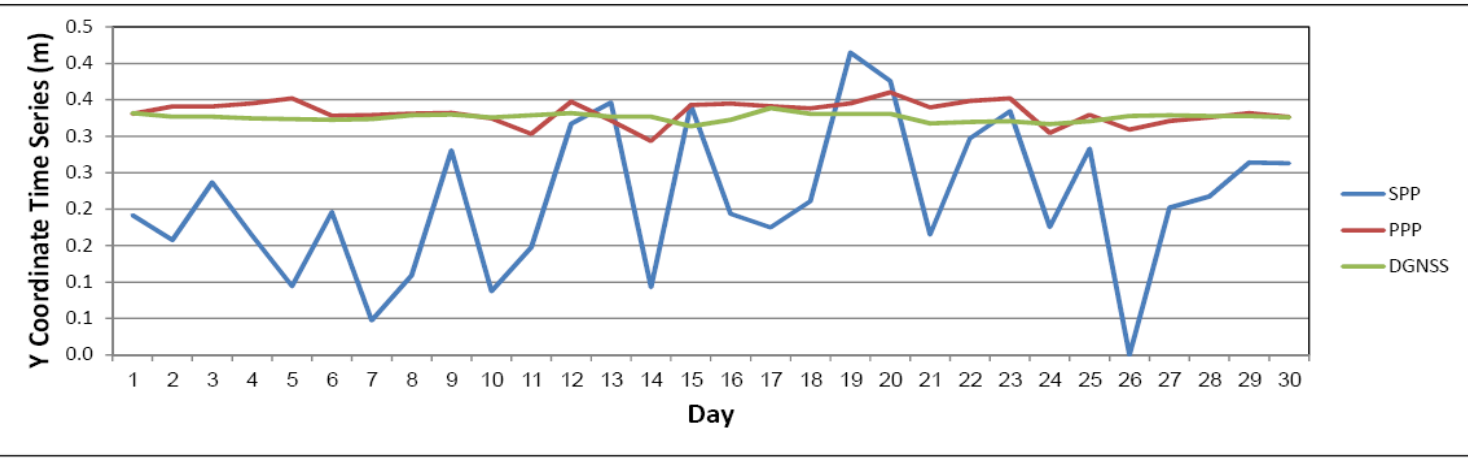

Fig. 3. Y coordinate time series over the month in case of the SPP, PPP and DGNSS solutions 


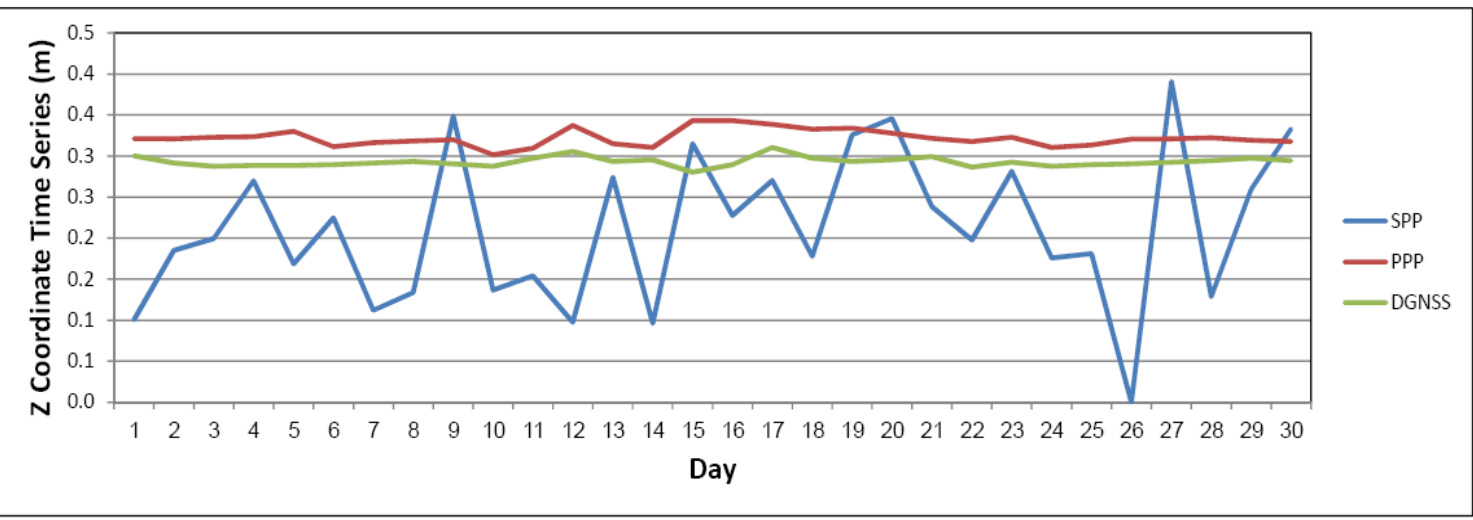

Fig. 4. Z coordinate time series over the month in case of the SPP, PPP and DGNSS solutions

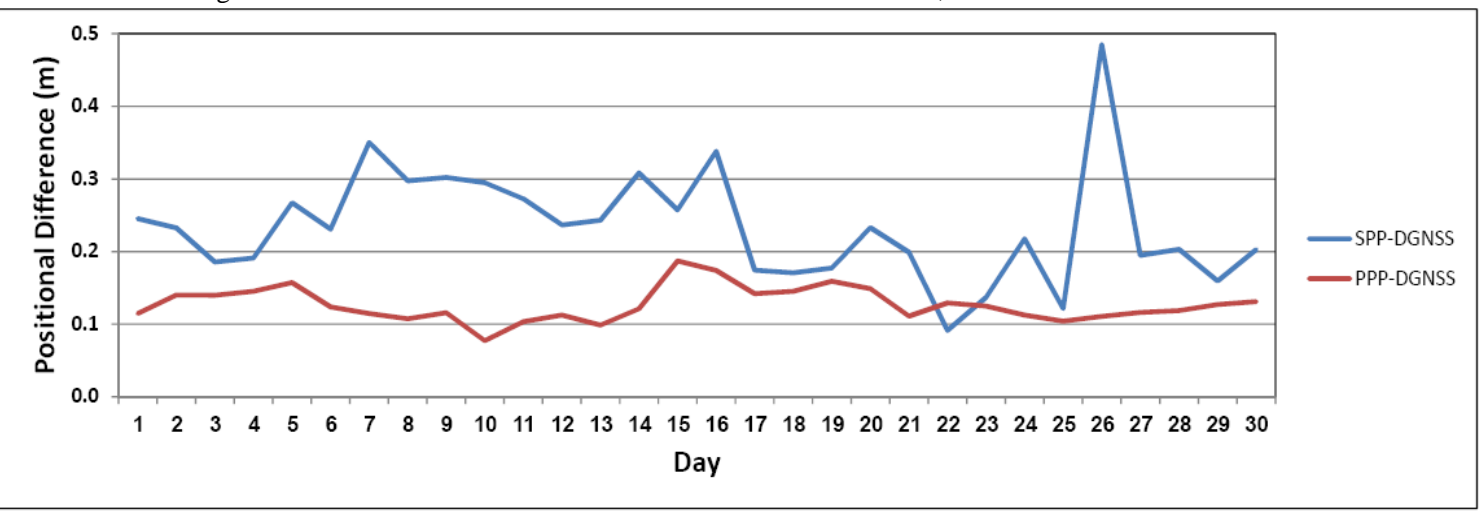

Fig. 5. Positional differences between DGNSS solutions and both SPP and PPP solutions over the month

Table IX and Figure 6 show statistics of the resulting daily differences between the PPP and DGNSS solutions.

TABLE IX. STATISTICS OF THE RESULTED DIFFERENCES BETWEEN PPP AND

\begin{tabular}{|c|c|c|c|c|}
\hline \multicolumn{1}{|c|}{ DGNSS SOLUTIONS OVER 30 DAYS } \\
\hline Value & $\Delta X_{P-D}$ & $\Delta Y_{P-D}$ & $\Delta Z_{P-D}$ & $\Delta P_{P-D}$ \\
\hline Minimum (m) & 0.076 & 0.001 & 0.012 & 0.077 \\
\hline Maximum (m) & 0.174 & 0.033 & 0.063 & 0.187 \\
\hline Mean (m) & 0.122 & 0.014 & 0.029 & 0.127 \\
\hline RMS (m) & 0.120 & 0.017 & 0.030 & 0.125 \\
\hline
\end{tabular}

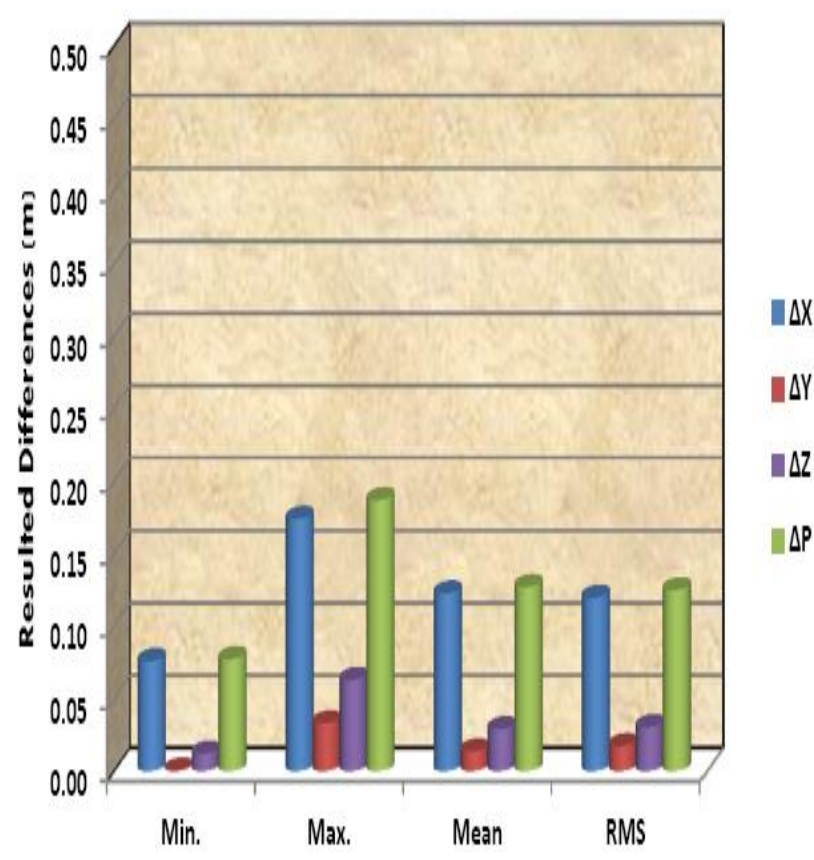

Fig. 6. Statistics of the resulted differences between the PPP and DGNSS solutions

On the other hand, Table X and Figure 7 shows statistics of the resulting daily differences between the SPP and DGNSS solutions. 
TABLE X STATISTICS OF THE RESULTED DIFFERENCES BETWEEN SPP AND DGNSS SOLUTIONS OVER 30 DAYS

\begin{tabular}{|c|c|c|c|c|}
\hline $\begin{array}{c}\text { Valu } \\
\mathrm{e}\end{array}$ & $\begin{array}{c}\Delta X_{P-D} \\
(\mathrm{~m})\end{array}$ & $\begin{array}{c}\Delta Y_{P-D} \\
(\mathrm{~m})\end{array}$ & $\begin{array}{c}\Delta Z_{P-D} \\
(\mathrm{~m})\end{array}$ & $\begin{array}{c}\Delta P_{P-D} \\
(\mathrm{~m})\end{array}$ \\
\hline Min. & 0.000 & 0.014 & 0.011 & 0.092 \\
\hline Max. & 0.306 & 0.328 & 0.291 & 0.485 \\
\hline Mean & 0.129 & 0.126 & 0.102 & 0.234 \\
\hline RMS & 0.151 & 0.151 & 0.123 & 0.246 \\
\hline
\end{tabular}

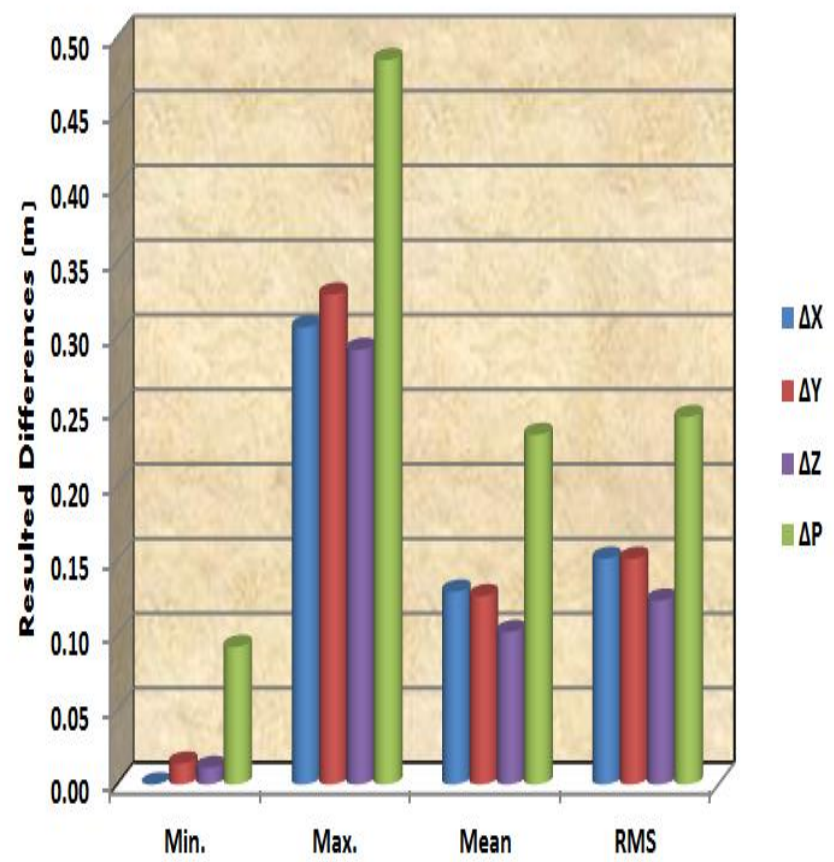

Fig. 7. Statistics of the resulted differences between the SPP and DGNSS solutions

If a unique monthly solution for each processing mode is considered, the weighted mean values of the processed days (30 days) have to be calculated. The resulted differences between the SPP solution and the DGNSS solution was found to be $15 \mathrm{~cm}$ in the positional difference. On the other hand, the resulted differences between the PPP solution and the DGNSS solution was found to be $12.5 \mathrm{~cm}$ in the positional difference. Thus, it is clear that the accuracy of both SPP and PPP techniques is very close to each other in case of considering a unique monthly solution.

\section{CONCLUSION}

An accuracy assessment for the SPP and PPP techniques was performed to evaluate the quality of applying both techniques in case of long observational periods. Data collected, from a continuous operating station at faculty of engineering, Ain Shams University, for June 2017 was used in this study. The final results showed that the SPP solutions had a positional difference with respect to the DGNSS solutions ranging from $9.2 \mathrm{~cm}$ to $48.5 \mathrm{~cm}$ with mean value $23.4 \mathrm{~cm}$ and RMS value $24.6 \mathrm{~cm}$ over the month. By considering a unique monthly solution (weighted mean value), the positional difference reaches to $15 \mathrm{~cm}$. On the other hand, the PPP solutions had a positional difference with respect to the DGNSS solutions ranging from $7.7 \mathrm{~cm}$ to $18.7 \mathrm{~cm}$ with mean value $12.7 \mathrm{~cm}$ and RMS value $12.5 \mathrm{~cm}$ over the month. By considering a unique monthly behavior, the positional difference reaches to $12.5 \mathrm{~cm}$. Finally, it is clear that the accuracy of both SPP and PPP techniques is very close to each other in case of considering a unique monthly solution. Thus, applications that do not require immediate positioning, such as wildlife management and insect infestation, can benefit from these results with low-cost hardware components. In addition, monitoring significant tectonic motions caused by earthquakes is another application that can benefit from these results keeping in mind that there will be no need to apply any postprocessing corrections to the measurements and thus, the system cost can be reduced significantly.

\section{REFERENCES}

[1] X. Meng, A.H. Dodson, T. Moore, and G. Roberts. Ubiquitous Positioning: Anyone, Anything, Anytime, Anywhere. GPS World, 18(6): 60-65, 2007.

[2] B. Hofmann-Wellenhof, H. Lichtenegger, and J. Collins. Global Positioning System, Theory and Practice, Fifth, revised edition. Springer-Verlag Wien GmbH, 2001

[3] T. Takasu. RTKLIB ver. 2.4.2 Manual, April 29, 2013.

[4] Trimble Inc. NetR9 GNSS Reference Receiver User Guide, version 4.15, revision A, May 2010.

[5] M. El-Tokhey, Y. M. Mogahed, M. Mamdouh, T. W. Hassan. Establishment of New Continuous Operating Reference Station (CORS) at Faculty of Engineering, Ain Shams University. International Journal of Engineering and Advanced Technology (IJEAT), ISSN: 2249 - 8958 , Volume-7 Issue-4, April 2018

[6] http://itrf.ensg.ign.fr/site info and select/ solutions extraction.php

[7] National Geospatial-Intelligence Agency (NGA). Department of Defense World Geodetic System 1984: Its Definition and Relationships with Local Geodetic Systems, July 8, 2014.

[8] C. C. Chang and H. Y. Lee. Performance of High Rate Interpolated Data Applied to GPS Kinematic Positioning. Survey Review, 43, 321 pp.303 313, DOI 10.1179/003962611X13055561708425, July 2011.

[9] T. Schüler. $10 \mathrm{~Hz}$ or $10 \mathrm{~s}$ ? GPS Solutions, 11:77-83, DOI 10.1007/s10291-006-0034-8, 2007.

[10] Mohd Hafiz Yahya and Md Nor Kamarudin. Analysis of GPS Visibility and Satellite-Receiver Geometry Over Different Latitudinal Regions. International Symposium on Geoinformation (ISG 2008) at: Kuala Lumpur, Malaysia, January 2008.

[11] I. F. Shaker, T. F. Fath-Allah, M. M. El-habiby, A. E. Ragheb and A. I. Awad. Enhancement of Precise Point Positioning Using GPS Single Frequency Data. International Journal of Scientific \& Engineering Research, Volume 7, Issue 12, December 2016. 